\title{
DUKUNGAN KELUARGA, SPRITUAL, MOTIVASI DENGAN KONDISI PSIKOLOGIS REMAJA PENGGUNA NARKOBA DI KOTA PAYAKUMBUH
}

\author{
Adriani $^{1}$ Khairul Abbas ${ }^{2 *}$ \\ STIKes Fort De Kock Bukittinggi \\ khairul_abbas15@yahoo.com
}

\section{Submitted: 12-12-2016, Reviewer: 12-12-2016, Accepted: 13-12-2016}

\begin{abstract}
Phenomena teenagers drug use now is often in find in social media. During undergo rehabilitation, junkies are often stress and depressed. Based on it, it would be better implanted attitude unyielding. The purpose of research to know whether there was an association family encouragement, spiritual, motivation with the psychological state of teenagers junkies in Lapas City Payakumbuh 2016. Research conducted in Lapas City Payakumbuh in February 2016. The methodology descriptive analytic to technique the sample accidental sampling use. The number of the sample sample about 36. Research results obtained respondents own support the bad 12 (33,3\%), support spiritual bad 13 (36,1\%), motivation bad 10 (27,8\%), the psychological state mal adaptive 11 (30,6\%). No relation support family psychological state of $p=1,000$. No relation to support spiritual psychological state of $p=0,475$. There is a psychological motivation with its worth $p=0,039$ and $O R=6,300$.

Based on thing over, concluded that there is a psychological motivation the teen drug users in lapas class iib city payakumbuh years 2016.
\end{abstract}

Key Words : Family, Spiritual, Motivation, Psychological.

\begin{abstract}
ABSTRAK
Fenomena remaja penggunaan narkoba sekarang ini sering di jumpai di media sosial. Selama menjalani rehabilitasi, para pecandu seringkali stres dan tertekan. Berdasarkan hal tersebut, akan lebih baik ditanamkan sikap pantang menyerah. Tujuan penelitian untuk mengetahui apakah ada hubungan dukungan keluarga, spritual, motivasi dengan kondisi psikologis remaja pengguna narkoba di Lapas Kota Payakumbuh tahun 2016.Penelitian dilakukan di Lapas Kota Payakumbuh pada bulan Februari 2016. Metode penelitian deskriptif analitik dengan teknik pengambilan sampel menggunakan accidental sampling. Jumlah sampel penelitian sebanyak 36 sampel. Hasil penelitian didapatkan responden memiliki dukungan keluarga buruk 12 (33,3\%), dukungan spritual buruk 13 (36,1\%), motivasi buruk 10 (27,8\%), kondisi psikologis mal adaptif $11(30,6 \%)$. Tidak ada hubungan dukungan keluarga dengan kondisi psikologis dengan nilai $\mathrm{p}=1,000$. Tidak ada hubungan dukungan spritual dengan kondisi psikologis dengan nilai $\mathrm{p}=0,475$. Ada hubungan motivasi dengan kondisi psikologis dengan nilai $\mathrm{p}=0,039$ dan $\mathrm{OR}=6,300$. Berdasarkan hal di atas, disimpulkan bahwa ada hubungan motivasi dengan kondisi psikologis remaja pengguna narkoba di Lapas Kota Payakumbuh tahun 2016.
\end{abstract}

Kata Kunci : Keluarga, Spritual, Motivasi, Psikologis. 


\section{PENDAHULUAN}

Fenomena penggunaan narkoba pada remaja sekarang ini sudah sering di jumpai di berbagai media sosial. Maraknya remaja yang terlibat dalam masalah belakangan ini menunjukan bahwa pada fase ini remaja sedang berada dalam masa yang sangat rentan akibat kurangnya pengalaman serta pemahaman pengetahuan yang diberikan tentang bahaya narkoba itu sendiri dan sudah semestinya masalah ini harus segera diselesaikan dengan penanganan yang cepat dan tepat serta dibutuhkan kerja sama antara masyarakat serta pihak atau lembaga terkait untuk penanganan masalah tentang narkoba (Kristanto, $2014: 65$ ).

Selama menjalani proses rehabilitasi, para pecandu narkoba seringkali stres dan berpikiran negatif karena tertekan oleh apa yang sedang dihadapinya. Berdasarkan hal tersebut, akan lebih baik bila pada para pecandu ditanamkan sikap pantang menyerah dengan keadaan yang sedang dihadapi (Noviarini, dkk, 2013: 117). Pitaloka, (dalam Primardi, 2010), Noviarini, dkk (2013: 117), menjelaskan bahwa kesuksesan seseorang dalam mencapai tujuan ditentukan oleh kemampuannya dalam mengatasi rintangan, stres, kemampuannya dalam menghasilkan emosi positif.

Selain itu, individu harus memiliki kesehatan jasmani dan rohani yang baik maka akan menghasilkan kualitas hidup yang baik pula, sehingga dapat menjalankan hidup di dalam masyarakat sesuai perannya masing-masing. Salah satu faktor yang dapat meningkatkan kualitas hidup adalah adanya dukungan sosial, apabila dukungan sosial berkurang maka kualitas hidup akan menurun. Angermeyer dkk (2002), Noviarini, dkk, (2013: 118).

Menurut Ceballo, dkk, Papalia, dkk (2008), Noviarini, dkk, (2013: 118), dalam lingkungan yang baik, dukungan sosial lebih efektif. Sumber dukungan sosial yang paling penting adalah dari pasangan, orang tua dan keluarga. Dengan pemahaman tersebut individu akan tahu kepada siapa ia akan mendapatkan dukungan sosial sesuai dengan situasi dan keinginan yang spesifik, sehingga dukungan sosial mempunyai makna berarti bagi kedua belah pihak.

Hasil penelitian Sujono (2008), Noviarini, dkk (2013: 118), menunjukkan bahwa sumber dukungan terbanyak yang paling sering diberikan adalah dari pasangan, keluarga dan orang tua karena mereka merupakan pihak yang paling dekat dan berkepentingan dengan klien. Orang-orang disekitar pecandu narkoba seperti teman dekat, dapat juga menjadi tempat curahan hati berbagai masalah yang dialami para pecandu, memberikan dukungan untuk sembuh dan tidak mudah putus asa dalam menjalani hidup. Dukungan yang diperoleh dari orang yang memiliki hubungan dekat berpengaruh terhadap peningkatan kesehatan.

Survei mengenai hubungan antara dukungan sosial dengan individu pada masa penyembuhan penyakit, ditemukan bahwa individu yang memiliki dukungan sosial akan lebih cepat mengalami penyembuhan dari waktu yang diperkirakan (Wallston, dkk, 2002), Noviarini, dkk (2013: 119). Dukungan sosial dapat bermanfaat positif bagi kesehatan bila individu merasakan dukungan tersebut sebagai dukungan yang layak dan sesuai dengan apa yang individu butuhkan (Sujono, 2008), Noviarini, dkk (2013: 118).

Selain itu, terapi keagamaan (psikoreligius) juga memegang peranan penting bagi para pecandu narkoba, baik dari segi pencegahan, terapi maupun rehabilitasi (Afni, dkk, 2013 : 118). Menurut Moore (dalam Alatas, 2006), Afni, dkk (2013: 118), bahwa orang yang tidak mempunyai komitmen agama akan beresiko empat kali lebih besar terlibat 
dalam penyalahgunaan dan ketergantungan narkoba, hasil penelitian ini mendukung hasil penelitian sebelumnya yang dilakukan oleh Comstock (dalam Alatas, 2006), Afni, dkk (2013 : 118), yang berkesimpulan pentingnya peranan agama dalam terapi dan rehabilitasi para penyalahguna atau ketergantungan narkoba.

$\begin{array}{cr}\text { Upaya } & \text { penanggulangan } \\ \text { penyalahgunaan } & \text { narkoba harus }\end{array}$ memerlukan kerjasama yang sinergis baik antara masyarakat maupun aparat penegak hukum serta pemerintah terkait baik di tingkat daerah maupun di tingkat pusat. Mengingat dampak yang di timbulkan kepada pecandu narkoba yang mempunyai di mensi luas dan komplek, baik dari sudut kesehatan jiwa dan psikososial. Terutama yang terkena adalah kaum remaja yang mana generasi penerus dan sekaligus potret bangsa untuk kedepannya.

Penerapan hukuman yang berat sesuai dengan Undang-Undang, masih dirasakan perlu untuk menerapkan efek jera, maupun rasa takut bagi para bandar maupun produsen narkoba, mengingat akibat yang di timbulkan begitu luas, serta berbahaya bagi kuantitas dan kualitas hidup generasi muda kita. Oleh sebab itu, tidak ada jalan lain bagi kita semua untuk menyatakan perang terhadap narkoba dengan melihat narkoba adalah sebagai musuh bersama. (Putra, 2011 : 4).

Hal ini merupakan dampak akibat dari pengaruh narkoba terhadap sistem saraf yang menjadi sulit dalam mengarah pada perilaku yang baik. Sehingga perlunya pembinaan yang sangat serius dan berkala untuk merubah perilaku kearah yang kita inginkan, baik terhadap mental, spritual dan kesadaran terhadap hukum dari akibat yang dilanggarnya. Selain itu, juga ada pembinaan dalam bidang keahlian atau keterampilan yang dimiliki narapidana. Hal ini berguna untuk pengalihan dari bentuk pekerjaan yang dilakukan menjadi positif.
Berpijak dari realita diatas, maka penulis tertarik dalam mengkaji dan melakukan penelitian untuk mendapatkan informasi, data dan menyimpulkan bagaimana pengaruh dukungan keluarga terhadap remaja pengguna narkoba yang sedang menjalani hukuman agar terciptanya kualitas hidup yang baik.

\section{METODE PENELITIAN}

Penelitian ini menggunakan metode deskriptif analitik dengan desain cross sectional yaitu suatu penelitian yang bertujuan untuk mempelajari dinamika hubungan antara faktor-faktor risiko dengan efek, dengan cara pendekatan, observasi atau pengumpulan data sekaligus pada suatu saat (Notoatmodjo, 2010: 37).

Pada penelitian ini yang menjadi populasi adalah keseluruhan remaja yang mempunyai keluarga dengan kasus pengguna narkoba di Lapas Kota Payakumbuh, yaitu sebanyak 50 orang (Data 24 Februari tahun 2016).

Sampel dalam penelitian diambil secara accidental sampling yang mana jumlah sampel diambil secara kebetulan adalah 36 orang remaja pada ruangan kejujuran dan ketabahan yang berstatus narapidana dengan kasus narkoba di Lapas Kota Payakumbuh, dengan kriteria Inklusi : Berusia 18 - 21 tahun, Belum menikah, Mempunyai keluarga, Mampu membaca dan menulis, Kriteria Ekslusi : Tidak bersedia menjadi responden, Tidak berada di tempat saat penelitian berlangsung

Penelitian ini dilakukan di Lapas Kota Payakumbuh pada tanggal 26 Februari-5 Maret 2016.

Instrumen penelitian terdiri dari angket tentang kondisi psikologis, dukungan keluarga, dukungan spritual, dan motivasi.

\section{HASIL DAN PEMBAHASAN}


Pada hasil penelitian ini akan membahas dukungan keluarga spiritual , motivasi dan kondisi psikologis

A. Analisis Univariat

1. Dukungan Keluarga

\begin{tabular}{cccc}
\hline No & $\begin{array}{c}\text { Dukungan } \\
\text { Keluarga }\end{array}$ & f & \% \\
\hline 1. & Buruk & 12 & 33,3 \\
2. & Baik & 24 & 66,7 \\
\hline & Jumlah & 36 & 100 \\
\hline
\end{tabular}

Berdasarkan diatas

diketahui bahwa dari 36 responden, tercatat 12 responden $33,3 \%$ dengan dukungan keluarga buruk.

2. Dukungan Spritual

\begin{tabular}{clcc}
\hline No & Dukungan Spritual & f & \% \\
\hline 1. & Buruk & 13 & 36,1 \\
2. & Baik & 23 & 63,9 \\
\hline \multicolumn{2}{r}{ Jumlah } & 36 & 100 \\
\hline & Berdasarkan & diatas
\end{tabular}

diketahui bahwa dari 36 responden, tercatat 13 responden $36,1 \%$ dengan dukungan spritual buruk.

3. Motivasi

\begin{tabular}{c|lcc}
\hline No & Motivasi & $\boldsymbol{f}$ & $\boldsymbol{\%}$ \\
\hline 1. & Buruk & 10 & 27,8 \\
2. & Baik & 26 & 72,2 \\
& Jumlah & 36 & 100 \\
\hline
\end{tabular}

Berdasarkan diatas diketahui bahwa dari 36 responden, tercatat 10 responden $27,8 \%$ dengan motivasi buruk.

4. Kondisi Psikologis

\begin{tabular}{clcc}
\hline No & Kondisi Psikologis & f & \% \\
\hline 1. & Mal Adaptif & 11 & 30,6 \\
2. & Adaptif & 25 & 69,4 \\
\hline & Jumlah & 36 & 100 \\
\hline
\end{tabular}

Berdasarkan tabel 5.4 diketahui bahwa dari 36 responden, tercatat 11 responden 30,6\% dengan kondisi psikologis mal adaptif.

\section{B. Analisis Bivariat}

1. Hubungan dukungan keluarga dengan Kondisi Psikologis

\begin{tabular}{|c|c|c|c|c|c|c|c|c|}
\hline \multirow{3}{*}{$\begin{array}{c}\text { Duk } \\
\text { unga } \\
\text { n } \\
\text { Kelu } \\
\text { arga }\end{array}$} & \multicolumn{4}{|c|}{$\begin{array}{c}\text { Kondisi } \\
\text { Psikologis }\end{array}$} & \multirow{2}{*}{\multicolumn{2}{|c|}{ Total }} & \multirow[t]{2}{*}{$\underset{\text { value }}{p}$} & \multirow[t]{2}{*}{ OR } \\
\hline & \multicolumn{2}{|c|}{$\begin{array}{c}\text { Mal } \\
\text { Adap } \\
\text { tif }\end{array}$} & \multicolumn{2}{|c|}{$\begin{array}{c}\text { Adapti } \\
\mathbf{f}\end{array}$} & & & & \\
\hline & $\mathbf{n}$ & $\%$ & $\mathbf{n}$ & $\%$ & $\mathbf{n}$ & $\%$ & 1,000 & 1,214 \\
\hline Buru & 4 & 33 & 8 & 66 & 1 & 10 & & \\
\hline $\mathrm{k}$ & &, 3 & &, 7 & 2 & 0 & & \\
\hline \multirow[t]{2}{*}{ Baik } & 7 & 29 & 1 & 70 & 2 & 10 & & \\
\hline & &, 2 & 7 & ,8 & 4 & 0 & & \\
\hline \multirow[t]{2}{*}{ Total } & 1 & 30 & 2 & 69 & 3 & 10 & & \\
\hline & 1 & 6 & 5 &, 4 & 6 & 0 & & \\
\hline
\end{tabular}

Hasil Analisa table diatas tentang Hubungan Dukungan Keluarga Dengan Kondisi Psikologis Remaja Pengguna Narkoba Di Lapas Kota Payakumbuh Tahun 2016 diperoleh bahwa dari 36 responden didapatkan dukungan keluarga buruk diperoleh hasil 4 (33,3\%) responden dengan kondisi psikologis mal adaptif dan $8(66,7 \%)$ responden dengan kondisi psikologis adaptif. Hasil uji statistik diperoleh nilai $\mathrm{p}=1,000$, maka dapat disimpulkan tidak ada hubungan dukungan keluarga dengan kondisi psikologis remaja pengguna narkoba di Lapas Kota Payakumbuh tahun 2016.

\section{Hubungan Dukungan Spiritual dengan Kondisi Psikologis}

\begin{tabular}{|c|c|c|c|c|c|c|c|c|}
\hline \multirow{3}{*}{$\begin{array}{l}\text { Duk } \\
\text { ung } \\
\text { an } \\
\text { Spri } \\
\text { tual }\end{array}$} & \multicolumn{4}{|c|}{$\begin{array}{c}\text { Kondisi } \\
\text { Psikologis } \\
\end{array}$} & \multirow{2}{*}{\multicolumn{2}{|c|}{ Total }} & \multirow[t]{3}{*}{$\begin{array}{c}\mathbf{p} \\
\text { value }\end{array}$} & \multirow[t]{3}{*}{ OR } \\
\hline & \multicolumn{2}{|c|}{$\begin{array}{c}\text { Mal } \\
\text { Adapti } \\
\mathbf{f}\end{array}$} & \multicolumn{2}{|c|}{$\begin{array}{c}\text { Adapti } \\
\mathbf{f}\end{array}$} & & & & \\
\hline & $\mathbf{n}$ & $\%$ & $\mathbf{n}$ & $\%$ & $\mathbf{n}$ & $\%$ & & \\
\hline Bur & 5 & 38 & 8 & 61 & 1 & 10 & 0,475 & 1,771 \\
\hline uk & &, 5 & &, 5 & 3 & 0 & & \\
\hline Bai & 6 & 26 & 1 & 73 & 2 & 10 & & \\
\hline $\mathrm{k}$ & &, 1 & 7 & ,9 & 3 & 0 & & \\
\hline Tota & 1 & 30 & 2 & 69 & 3 & 10 & & \\
\hline 1 & 1 & 6 & 5 &, 4 & 6 & 0 & & \\
\hline
\end{tabular}

Hasil Analisa table diatas tentang Hubungan Dukungan Spritual Dengan Kondisi Psikologis Remaja Pengguna Narkoba Di Lapas Kota Payakumbuh Tahun 2016 diperoleh bahwa dari 36 responden didapatkan dukungan spritual buruk diperoleh hasil 5 (38,5\%) responden dengan kondisi psikologis mal 
adaptif dan $8(61,5 \%)$ responden dengan kondisi psikologis adaptif. Hasil uji statistik diperoleh nilai $\mathrm{p}=0,475$, maka dapat disimpulkan tidak ada hubungan dukungan spritual dengan kondisi psikologis remaja pengguna narkoba di Lapas Kota Payakumbuh tahun 2016.

\section{Hubungan Motivasi dengan Dukungan Psikologis}

\begin{tabular}{|c|c|c|c|c|c|c|c|}
\hline \multirow{3}{*}{$\begin{array}{c}\text { Motiv } \\
\text { asi }\end{array}$} & \multicolumn{4}{|c|}{ Kondisi Psikologis } & \multirow{2}{*}{\multicolumn{2}{|c|}{ Total }} & \multirow{3}{*}{$\begin{array}{c}\mathbf{p} \\
\text { valu } \\
\mathbf{e}\end{array}$} \\
\hline & \multicolumn{2}{|c|}{$\begin{array}{c}\text { Mal } \\
\text { Adaptif }\end{array}$} & \multicolumn{2}{|c|}{ Adaptif } & & & \\
\hline & $\mathbf{n}$ & $\%$ & $\mathbf{n}$ & $\%$ & $\mathbf{n}$ & $\%$ & \\
\hline Buruk & 6 & $\begin{array}{c}60, \\
0\end{array}$ & 4 & $\begin{array}{c}40, \\
0\end{array}$ & $\begin{array}{l}1 \\
0\end{array}$ & 100 & $\begin{array}{c}0,03 \\
9\end{array}$ \\
\hline Baik & 5 & $\begin{array}{c}19, \\
2\end{array}$ & $\begin{array}{l}2 \\
1\end{array}$ & $\begin{array}{c}80, \\
8\end{array}$ & $\begin{array}{l}2 \\
6\end{array}$ & 100 & \\
\hline Total & $\begin{array}{l}1 \\
1\end{array}$ & $\begin{array}{c}30, \\
6\end{array}$ & $\begin{array}{l}2 \\
5\end{array}$ & $\begin{array}{c}69, \\
4\end{array}$ & $\begin{array}{l}3 \\
6\end{array}$ & 100 & \\
\hline
\end{tabular}

Hasil Analisa tabel 5.7 tentang Hubungan Motivasi Dengan Kondisi Psikologis Remaja Pengguna Narkoba Di Lapas Kota Payakumbuh Tahun 2016 diperoleh bahwa dari 36 responden didapatkan motivasi buruk diperoleh hasil $6(60,0 \%)$ responden dengan kondisi psikologis mal adaptif dan 4 $(40,0 \%)$ responden dengan kondisi psikologis adaptif.

Hasil uji statistik diperoleh nilai $\mathrm{p}=0,039$, maka dapat disimpulkan ada hubungan motivasi dengan kondisi psikologis remaja pengguna narkoba di Lapas Kota Payakumbuh tahun 2016. Dari hasil analisa diperoleh nilai $\mathrm{OR}=6,300$, artinya responden yang melakukan dukungan keluarga yang baik mempunyai nilai peluang 6,300 kali mengalami kondisi psikologis adaptif dibandingkan dengan responden yang memiliki dukungan keluarga buruk.
Berdasarkan hasil penelitian dan pembahasan tentang hubungan dukungan keluarga, dukungan spritual, motivasi dengan kondisi psikologis remaja pengguna narkoba di Lapas Kota Payakumbuh tahun 2016 dapat disimpulkan bahwa responden yang memiliki dukungan keluarga buruk 12 $(33,3 \%)$, responden yang memiliki dukungan spritual buruk $13(36,1 \%)$, ORsponden yang memiliki motivasi buruk $10(27,8 \%)$, responden yang memiliki kondisi psikologis mal adaptif 11 $(30,6 \%)$, tidak ada hubungan dukungan Feluarga dengan kondisi psikologis dengan nilai $\mathrm{p}=1,000$, tidak ada hubungan dukungan spritual dengan kondisi psikologis dengan nilai $\mathrm{p}=0,475$, ada hubungan motivasi dengan kondisi psikologis dengan nilai $\mathrm{p}=0,039$ dan $\mathrm{OR}=6,300$. Dari hasil penelitian yang dilakukan maka disarankan kepada bagi remaja pengguna narkoba hendaknya remaja pengguna narkoba yang sedang menjalani hukuman lebih meningkatkan lagi rasa motivasi yang tinggi dan keyakinan yang kuat untuk keluar dari masalah yang dihadapi serta meningkatkan rasa spritual agar menjadi pribadi yang lebih baik lagi untuk kedepannnya. Bagi keluarga hendaknya dalam memberikan dukungan kepada remaja harus maksimal demi untuk meningkatkan motivasi remaja untuk sembuh dan keluar dari jeratan hukum sangat tinggi. Kerena keluarga adalah orang terdekat bagi remaja. Bagi masyarakat hendaknya dapat menerima remaja seperti masyarakat biasanya dan jangan mengucilkan dalam hubungan sosial di tengah masyarakat setelah remaja selesai menjalani hukuman dan kembali ke masyarakat agar tidak menjadi harga diri rendah. 
Puji syukur yang tak terhingga penulis ucapkan kehadirat Allah SWT yang telah melimpahkan rahmat dan hidayahNya. Penulis mengucapkan terimakasih kepada kedua orang tua tercinta yang telah memberikan penulis cinta dan kasih sayang yang tulus,"Jasamu Takkan Pernah Terbalas Sampai Kapanpun Jua”. Selain itu, uacapan terima kasih juga penulis ucapkan kepada abang dan uni serta keponakan tersayang penulis, yaitu bang Acep dan uni Eni serta Faiz dan Acha yang selalu memberikan penulis dukungan dan semangat serta segala pengorbannya.

\section{DAFTAR PUSTAKA}

Allas, H. 2006. Penanggulangan Korban Narkoba, Jakarta : Balai Penerbit Fakultas Kedokteran Universitas Indonesia,

Amriel, R. I. 2008 Psikologi Kaum Muda Pengguna Narkoba, Jakarta : Salemba Humanika

Aris, K. 2014 Bentuk Dukungan Keluarga Terhadap Remaja Pengguna Narkoba (Studi Kasus Di Yayasan Borneo Insan Mandiri Samarinda). Journal.

Bayu, P. 2011 Hubungan Antara Dukungan Sosial Dengan Motivasi Untuk Sembuh Pada Pengguna Napza Di Rehabillitasi Madani Mental Health Care. Fakultas Psikologi Universitas Islam Negeri Syarif Hidayatullah, Jakarta, 2011.

Bernadette. W., dkk. 2008. The Role Of Families In Preventing AlcoholRelated Harm Among Young People. School of Psychology, Psychiatry and Psychological Medicine, Monash University. .
Brad Lundahl, dkk. 2009. The Effectiveness And Applicability Of Motivational Interviewing: A Practice Friendly Review of Four Meta-Analyses. University of Utah.

Carlo C., Di Clemente, dkk. 1999. Motivation For Change And Alcoholism Treatment.

Dadang Hawari. 2008 Manajemen Stres Cemas Dan Depresi, Jakarta : Balai Penerbit Fakultas Kedokteran Universitas Indonesia.

Fadzli Adam, dkk, 2011. Spiritual And Traditional Rehabilitation Modality of Drug Addiction In Malaysia. Department of General Studies, Faculty of Social Development Universiti Malaysia Terengganu (UMT) 21030 Kuala Terengganu Malaysia.

Hawari, D, 2006. Penyalahgunaan Dan Ketergantungan NAZA (Narkotika, Alkohol, Dan Zat Adiktif), Jakarta : Balai Penerbit Fakultas Kedokteran Universitas Indonesia,

Herri Zan Pieter, Bethsaida Janiwarti, dkk, 2011 Pengantar Psikologi Untuk Keperawatan, Jakarta : Kencana Prenada Media Group.

Karina, D., K. dkk. 2012 Peran Pendampingan Spiritual Terhadap Motivasi Kesembuhan Pada Pasien Lanjut Usia. STIKES RS. Baptis Kediri.

Kementerian Kesehatan RI, 2014. Buletin Jendela (Data dan Informasi Kesehatan). Jakarta. 
Kenneth, J., G. dkk. 2006 A Family Perspective For Substance Abuse : Implications From The Literature.

Mansur, A, 2014 Perspectives On Drug Addiction In Islamic History and Theology. Centre for the Study of Islam in the UK, School of History, Archaeology and Religion, John Percival Building, Cardiff University, Colum Drive, Cardiff CF10 3EU..

Nur, A., Noviarini., Mahargyantari., dkk. 2013 Hubungan Antara Dukungan Sosial Dengan Kualitas Hidup Pada Pecandu Narkoba Yang Sedang Menjalani Rehabilitasi. Fakultas Psikologi Universitas Gunadarma, Depok.

Padila, 2012 Buku Ajar Keperawatan Keluarga, Yogyakarta : Nuha Medika.

Purwanto, N. 2004. Psikologi Pendidikan, Bandung : PT Remaja Rosdakarya.

Rahmat, A. 2011 Pengalaman Spiritual Dan Kebahagiaan Pada Guru Agama Sekolah Dasar. Fakultas Psikologi Universitas Islam Negeri Malang.

Reni, D., S. Dkk 2013. Hubungan Tingkat Kecerdasan Spiritual Dengan Mekanisme Koping Pada Remaja Di SMAN 2 Purwokerto. Program Studi S1 Keperawatan STIKES Harapan Bangsa Purwokerto.

Roger, H., Peters, dkk. 2015 CoOccurring Substance Use And Mental Disorders In The Criminal Justice System : A New Frontier Of Clinical Practice And
Research. University of South Florida.

Sarlito W., S. 2012. Psikologi Remaja, Jakarta : PT Raja Grafindo Persada

Sunaryo, 2013. Psikologi Untuk Keperawatan ED.2, Jakarta: Penerbit Buku Kedokteran EGC..

Willis, S. S. 2005 Remaja Dan Masalah Mengupas Berbagai Bentuk Kenakalan Remaja Seperti Narkoba, Free Sex, Dan Pemecahannya, Bandung : Alfabeta..

Wresniwiro, M., dkk. 1999. Masalah Narkotika, Psikotropika, Dan Obat-Obatan Berbahaya, Jakarta : Bina Dharma Muda, 1999.

Yulia, I., Widodo. H., dkk, 2009 Hubungan Antara Dukungan Keluarga Dengan Keinginan Untuk Sembuh Pada Penyalahgunaan Napza Di Lembaga Pemasyarakatan Wirogunan Kota Yogyakarta. Fakultas Kesehatan Masyarakat Universitas Ahmad Dahlan, Yogyakarta.

Zamzami, S., M. As'ad, D, dkk. 2012. Kecerderdasan Emosi Kecerdasan Spiritual dan Perilaku Prososial Santri Pondok Pesantren Nasyrul Ulum Pamekasan. SMA Sabilul Ihsan Pamekasan. 